\title{
An Evaluation to Banking Frauds integrated with Technological Understanding
}

\author{
Ashish Ravindra Soni \\ Sr. Specialist QA Engineer, Pune
}

\author{
U. A. Lanjewar, PhD \\ Director, VMV Commerce College, Nagpur
}

\begin{abstract}
The Indian financial segment has encountered impressive development and changes since progression of economy in 1991. In spite of the fact that the financial business is commonly all around controlled and administered, the area experiences its very own arrangement of difficulties with regards to moral practices, money related trouble and corporate administration. This examination attempts to cover issues, for example, banking fakes and mounting Visa obligation, with a point by point investigation utilizing optional information (writing survey and case approach) just as a meeting based methodology, traversing over all players associated with detailing budgetary unfortunate behavior. The report contacts upon the instance of rising NPAs in the previous couple of years crosswise over different planned business banks, particularly open division banks. The investigation at last proposes a few proposals to decrease future event of cheats in Indian financial area. The validity of outsiders, for example, examining firms and FICO score organizations is additionally addressed in the examination and is accepted to be a noteworthy benefactor among different causes, for example, oversight by banks and insufficient perseverance.
\end{abstract}

\section{Keywords}

Non-performing assets, Stressed assets, Banking frauds

\section{INTRODUCTION}

Lately, occasions of money related misrepresentation have routinely been accounted for in India. In spite of the fact that financial fakes in India have regularly been treated as expense of working together, post progression the recurrence, multifaceted nature and cost of banking fakes have expanded complex bringing about an intense reason for worry for controllers, for example, the Reserve Bank of India (RBI). RBI, the controller of banks in India, characterizes misrepresentation as "A purposeful demonstration of oversight or commission by any individual, did throughout a financial exchange or in the books of records kept up physically or under PC framework in banks, coming about into improper increase to any individual for a transitory period or something else, with or with no money related misfortune to the bank". 2 Over the most recent three years, open segment banks (PSBs) in India have lost an aggregate of Rs. 22,743 center, by virtue of different financial cheats. With different measures started by the RBI, quantities of banking misrepresentation cases have declined, however measure of cash lost has expanded in these years. At first sight, an underlying examination in these cases has uncovered inclusion of midlevel workers, yet in addition of the senior most administration as was reflected on account of Syndicate Bank and Indian Bank. This raises genuine worry over the adequacy of corporate administration at the most astounding echelons of these banks. Furthermore, there has been a rising pattern of non-performing resources (NPAs), particularly for the PSBs, accordingly seriously affecting their benefit. A few causes have been credited to dangerous NPAs, including worldwide and local lull, yet there is some proof of a connection among fakes and NPAs.

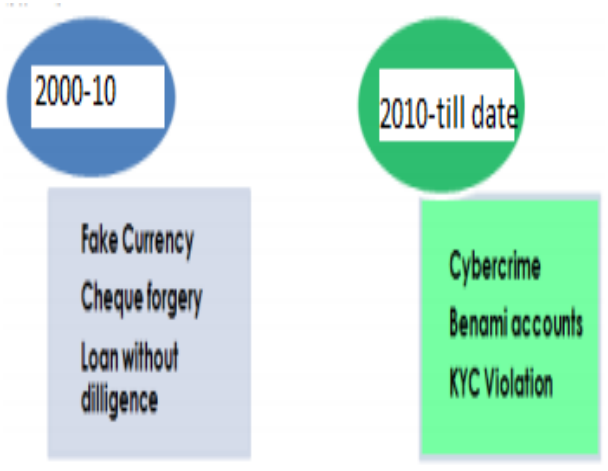

Figure-1: Banking Frauds

Bank extortion is the utilization of possibly unlawful intends to get cash, resources, or other property claimed or held by a budgetary organization, or to acquire cash from investors by falsely acting like a bank or other money related institution.[1] In numerous examples, bank misrepresentation is a criminal offense. While the particular components of specific financial extortion laws change contingent upon wards, the term bank misrepresentation applies to activities that utilize a plan or ingenuity, rather than bank burglary or robbery. Hence, bank misrepresentation is some of the time thought about a salaried wrongdoing.

\section{TYPES OF BANK FRAUD Bookkeeping extortion}

So as to stow away genuine budgetary issues, a few organizations have been known to utilize fake accounting to exaggerate deals and salary, blow up the value of the organization's advantages, or express a benefit when the organization is working at a misfortune. These altered records are then used to look for interest in the organization's security or security issues or to make false advance applications in a last endeavor to acquire more cash to postpone the inescapable breakdown of an unfruitful or bungled firm.

\section{Request draft misrepresentation:}

Request draft (DD) misrepresentation regularly includes at least one degenerate bank representatives. Right off the bat, such representatives expel a couple of DD leaves or DD books from stock and keep in touch with them like an ordinary DD. Since they are insiders, they know the coding and punching of an interest draft. Such false interest drafts are normally drawn payable at a removed city without charging a record. The draft is gotten the money for at the payable branch. The misrepresentation is found just when the bank's head office does the branch-wise compromise, which ordinarily take a half year, by which time the cash is no more. 


\section{Remotely made check extortion:}

Remotely made checks are requests of installment made by the payee and approved by the client remotely, utilizing a phone or the web by giving the required data including the MICR code from a substantial check. They don't bear the marks of the clients like standard checks. Rather, they bear a legend proclamation "Approved by Drawer". This kind of instrument is normally utilized with Visa organizations, service organizations, or telemarketers. The absence of mark makes them vulnerable to misrepresentation. The extortion is viewed as DD misrepresentation in the US.

\section{Uninsured stores :}

Bank requesting open stores might be uninsured or not authorized to work by any means. The goal is as a rule to request for stores to this uninsured "bank", albeit some may likewise sell stock speaking to responsibility for "bank". Now and again the names seem official or fundamentally the same as those of authentic banks. For example, the unlicensed "Pursue Trust Bank" of Washington D.C. showed up in 2002, bearing no connection to its apparently clear namesake; the genuine Chase Manhattan Bank[3] is situated in New York. Bookkeeping misrepresentation has likewise been utilized to cover other burglary occurring inside an organization.

\section{Bill limiting extortion:}

Basically a certainty trap, a fraudster utilizes an organization available to them to pick up the bank's certainty, by acting like a veritable, beneficial client. To give the figment of being an ideal client, the organization normally and over and again utilizes the bank to get installment from at least one of its clients. These installments are constantly made, as the clients being referred to are a piece of the misrepresentation, effectively paying all bills the bank endeavors to gather. After the fraudster has picked up the bank's trust, the organization demands that the bank start paying the organization in advance for bills it will gather from the clients later. Numerous banks will concur, however are not prone to go entire hoard immediately. So once more, business proceeds as typical for the deceitful organization, its fake clients, and the accidental bank. As the bank develops progressively OK with the plan, it will confide in the organization to an ever increasing extent and be eager to give it bigger and bigger wholes of cash in advance. In the end, when the exceptional harmony between the bank and the organization is adequately vast, the organization and its clients vanish, taking the cash the bank paid in advance and leaving nobody to pay the bills issued by the bank.

\section{Duplication or skimming of card data:}

This takes various structures, running from vendors duplicating customers' Mastercard numbers for use in later unlawful exercises or culprits utilizing duplicates from old mechanical card engrave machines to take the data, to the utilization of altered credit or plastic perusers to duplicate the attractive stripe from an installment card while a concealed camera catches the numbers on card.

\section{Installment card misrepresentation:}

Charge card misrepresentation is across the board as a methods for taking from banks, traders and customers. Sponsor checks A supporter check is a deceitful or terrible check used to make an installment to a charge card account so as to "break out" or raise the measure of accessible credit on something else authentic Mastercards. The measure of the check is credited to the card account by the bank when the installment is made, despite the fact that the check has not yet cleared. Before the terrible check is found, the culprit goes on a spending binge or acquires loans until the recently "raised" accessible cutoff on the card is come to. The first check at that point skips, however by then it is as of now past the point of no return.

\section{Stolen installment cards}

Regularly, the principal sign that an unfortunate casualty's wallet has been stolen is a telephone call from a Mastercard guarantor inquiring as to whether the individual has gone on a spending binge; the least complex type of this robbery includes taking the card itself and charging various high-ticket things to it in the initial couple of minutes or hours before it is accounted for as stolen.

\section{Phishing and Internet extortion:}

Phishing, otherwise called Internet misrepresentation, works by sending fashioned email, mimicking an online bank, closeout or installment website; the email guides the client to a produced site which is intended to resemble the login to the authentic webpage however which guarantees that the client must refresh individual data. The data accordingly stolen is then utilized in different fakes, for example, robbery of character or online sale extortion.

\section{Prime bank misrepresentation:}

The "prime bank" activity which professes to offer a critical, selective chance to take advantage of the best-stayed discreet in the financial business, ensured stores in "prime banks", "protected banks", "monetary certificates and bank-issued debentures from top 500 world banks", "bank assurances and backup letters of credit" which produce terrific returns at no hazard and are "supported by the World Bank" or different national governments and national investors. Be that as it may, these official-sounding expressions and more are the sign of the alleged "prime bank" extortion; they may sound extraordinary on paper, yet the ensured seaward speculation with the dubious cases of a simple $100 \%$ month to month return are on the whole imaginary money related instruments expected to swindle people.

\section{Rebel brokers:}

A rebel broker is a dealer at a money related establishment who takes part in unapproved exchanging to recover the misfortune they brought about in before exchanges. Out of dread and edginess, they control the inside controls to bypass discovery to purchase more time.[10]

Lamentably, unapproved exchanging exercises constantly produce more misfortunes because of time requirements; most maverick dealers are found at a beginning period with misfortunes running from $\$ 1$ million to $\$ 100$ million, however a not many working out of foundations with very careless controls were not found until the misfortune had achieved well over a billion dollars. The extent of the misfortune is an impression of the laxity in controls established at the firm and not the broker's insatiability. In opposition to the open observation, maverick brokers don't have criminal purpose to swindle their manager to advance themselves; they are only attempting to recover the misfortune to make their firm entire and rescue their employment.[10]

\section{LITERATURE REVIEW}

Mergers of goliaths in the financial business brought forth the idea of "too enormous to come up short", which in the end prompted exceptionally dangerous budgetary destinations and monetary emergency of 2008. Because of the 2008 emergency, Dodd-Frank divider road change and purchaser assurance act (DFA) was instituted in 2010. DFA brought 
forth different new organizations to help screen and avoid deceitful practices. Volcker rule, a piece of DFA, restricted banks from taking part in exclusive exchanging activities for benefit. Post emergency, IMF has moved in the direction of making danger and vulnerabilities appraisal system successful, by upholding more noteworthy straightforwardness and data sharing, alongside enabled supervisory and administrative bodies, just as more prominent worldwide coordinated effort towards guideline and supervision of budgetary organizations. Holes were recognized under money related observation just as on the recurrence of such reconnaissance particularly in economies with genuinely fundamental monetary areas, whose disappointment may trigger a budgetary emergency. As per writing, roughly one of every three financial emergencies pursued a credit blast, which demonstrates a connection between's casual credit extension arrangements by banks and emergencies. Another significant division upset with fake practices is the Mastercard advertise.

Be that as it may, given that Visa utilization in India is dominatingly for value-based purposes, the macroeconomic effect of fake practices is less huge and isn't viewed as further in this investigation. Indian financial framework has remained tormented with development in NPAs amid ongoing years, which brought about an endless loop influencing its maintainability. Chakrabarty (2013) noted in his discourse that, while most quantities of cheats have been ascribed to private and remote banks, open part banks have made the most noteworthy commitment towards the sum included. Key discoveries in RBI (2014b) incorporated the worry of benefit quality and peripheral capitalization looked by open area banks, and different suggestions to address these issues.

Rajan (2014) worried on great administration and more selfgovernance to be presented to open division banks IIMB-WP N0. $5056 \mid \mathrm{P}$ a g e to build their intensity and to have the capacity to fund-raise from business sectors effectively. In light of the basic discernment that inexorably severe guidelines will make business openings endure a shot, Raju (2014) expressed that, guidelines don't appear to be a bar in working of banks after the emergency. Subbarao (2009) was of the feeling that without expansive based trust and assumption of legitimate conduct, there wouldn't be a budgetary part of the present scale and size. He called the rise of an ethical danger issue in the financial framework as privatization of benefit and socialization of expenses.

To keep up consistency in misrepresentation revealing, cheats have been arranged by RBI dependent on their sorts and arrangements of the Indian correctional code, and announcing rules have been set for those as indicated by RBI (2014a and 2015a). Towards observing of fakes by the top managerial staff, a roundabout was issued according to RBI (2015b) to agreeable banks to set up a board to administer inner investigation and inspecting, and plan on fitting preventive activities, trailed by audit of viability of those activities. Fairminded arrangement rules and informant approach are imperative to enable workers to deal with cheats. RBI additionally issued a roundabout and presented the idea of red hailed account (RFA), in light of the nearness of early cautioning signs (EWS), into the present structure, for early recognition and avoidance of cheats. Gandhi (2014) talked about the prime reasons for developing NPAs and perceived the nonappearance of vigorous credit evaluation framework, wasteful supervision post credit disbursal, and incapable recuperation system as key boundaries tending to those viewpoints. Gandhi (2015) worried on the fundamental rules that can go far in avoiding extortion, to be specific the standards of knowing the client and representatives just as accomplices. He likewise called attention to the importance of a vigorous examination component and consistent observing.

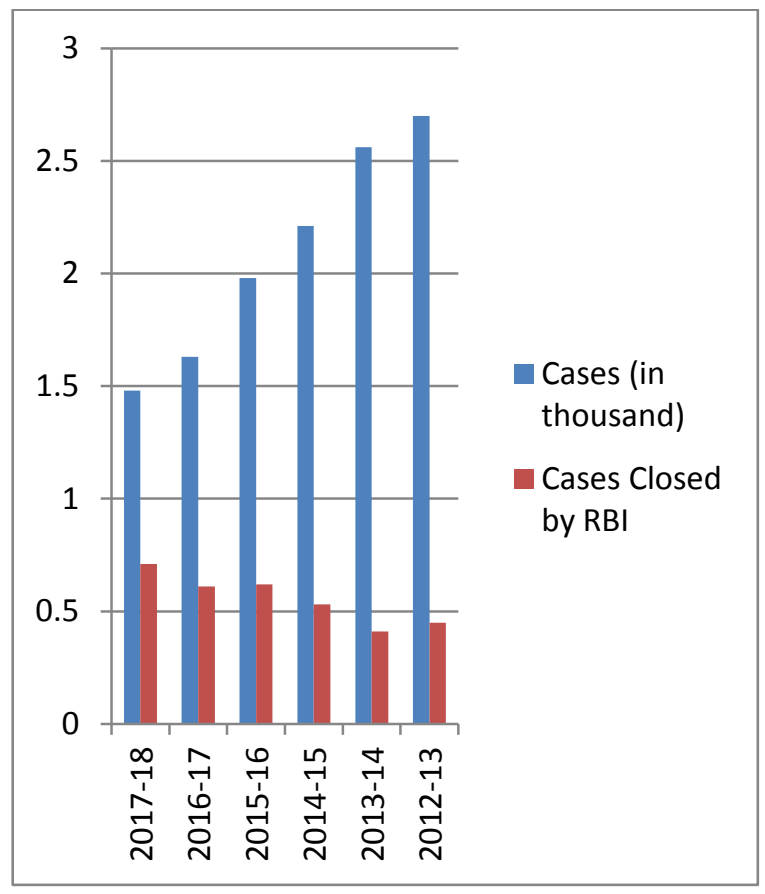

Figure-2: Number of bank fraud cases Registered

Table-1: ATM and POS Transactional statistic.

\begin{tabular}{|c|c|c|c|}
\hline & Mar-18 & Mar-14 & $\begin{array}{l}\text { Multiplying } \\
\text { factor }\end{array}$ \\
\hline $\mathrm{N}_{0,0 \text { of ATMs }}$ & 199099 & 95686 & 2,08 \\
\hline No. of ATM transactions & 732334436 & 471233729 & 1.55 \\
\hline Amount of ATM Transactions (In INR Cr.) & 224862.4 & 131837.6 & 1.71 \\
\hline No. POS Terminals & 1385668 & 660920 & 2.10 \\
\hline N0. of POS transactions & 185088730 & 59413631 & 3.12 \\
\hline Amount of POS transactions (In INR Cr.) & 36157.4 & 13490.7 & 2.68 \\
\hline $\mathrm{N}_{0,0}$ of Credit cards & 24505219 & 17653818 & 1.39 \\
\hline $\mathrm{N}_{0, \text { of Dehit Cards }}$ & 6661824092 & 278282839 & 2.38 \\
\hline
\end{tabular}

\section{BANKING TECHNOLOGICAL UNDERSTANDING:}

Hacking: Hackers/fraudsters get unapproved access to the card the board arrangement of the individual bank. Fake cards are then issued with the end goal of tax evasion.

Phishing: A procedure used to get your card and individual subtleties through a phony email

Pharming: A comparative procedure where a fraudster introduces noxious code on a PC or server. This code at that point diverts clicks you make on a Website to another fake Website without your assent or learning Frauds In Indian Banking: Aspects, Reasons, Trend-Analysis And Suggestive Measures 
Vishing: Fraudsters likewise utilize the telephone to request your own data.

Smishing: It utilizes phone instant messages to draw purchasers in. Regularly the content will contain a URL or telephone number. The telephone number frequently has a mechanized voice reaction framework. What's more, again simply like phishing, the smishing message for the most part requests your prompt consideration.

Check card skimming: A machine or camera is introduced at an ATM which grabs card related data and PIN numbers when clients utilize their cards.

PC infections: With each snap on the web, an organization's frameworks are available to the danger of being tainted with loathsome programming that is set up to gather data from the organization servers.

Fake instruments: Fake checks/Demand Drafts that look pipe dream are being utilized in a developing number of deceitful plans, including remote lottery tricks, check excessive charge tricks, web sell off tricks and mystery customer tricks. With the developing business of portable banking, it is fundamental that we commit selective existence to this angle/method of banking.

\section{Conceivable cheats with Mobile Banking:}

Counterfeit applications: The initial phase in taking cash online is to take data. This should be possible by making a phony application outside a play store. Programmers make counterfeit applications which will looks precisely as the first one and the utilization and interface is like the first application.

Portable financial application being mapped to an off base versatile number: For bank clients who don't utilize versatile banking, a worker of the bank could connect a partner's versatile number to the ledger and introduce a portable application on his cell phone. The client's record is undermined by the partner and the person does not get any notice about the equivalent.

SIM Swap: The fraudsters will initially gather the individual financial data through phishing, vishing, smishing or some other methods. When they have the equivalent, they figure out how to have the SIM card blocked, and get a copy one by visiting the portable administrator's retail outlet with phony character evidence. The portable administrator deactivates the authentic SIM card, which was blocked, and issues another SIM to the fraudsters. It is currently easy to create a one-time secret phrase (OTP) required for exchanges utilizing the stolen financial data. This OTP is gotten on the new SIM held by the fraudsters and they would now be able to execute before the bank client understands the burglary and alarms the bank.

Conceivable cheats with Mobile Wallets: Increased danger of illegal tax avoidance: Transfer of cash into and out of a versatile wallet (with open and semiopen wallet choice accessible) from or to a ledger is presently conceivable. Money in from the financial balance of an individual and money out to an alternate ledger of another individual can be utilized as a stage for laundering unaccounted cash.

Counterfeit vendors: If the shipper on-boarded by the specialist co-op is a fraudster, and the installment is made by the client for invented merchandise or administrations from the dealer, money can be charged from the record. Selection of versatile business is subject to clients' recognitions about how safe their virtual cash is from extortion. After some time, the capacity to effectively counter cheats can turn into a key business differentiator for portable wallet organizations. Misrepresentation, along these lines should be considered as a basic business chance as opposed to only a coincidental monetary misfortune.

\section{ANALYSIS AND DISCUSSION}

According to the RBI, bank cheats can be grouped into three general classifications: store related fakes, progresses related fakes and administrations related fakes. Store related fakes, which used to be critical as far as numbers however not in size, have descended altogether lately, inferable from another arrangement of installment, and presentation of check truncation framework (CTS) by business banks, utilization of electronic exchange of reserve, and so on. Advances related extortion keep on being a noteworthy test as far as sum included (about 67 percent of aggregate sum associated with fakes over most recent 4 years), representing an immediate risk to the budgetary security of banks. With regularly expanding utilization of innovation in the financial framework, digital cheats have multiplied and are winding up significantly increasingly complex as far as utilization of novel techniques. Likewise, narrative credit (letter of credit) related fakes have surfaced causing a grave worry because of their suggestions on exchange and related exercises. The information uncovers that in excess of 95 percent of number of extortion cases and sum associated with misrepresentation originates from business banks. Among the business banks, open area banks represent pretty much 18 percent of absolute number of extortion cases, though as far as the sum included, the extent goes as high as 83 percent. This is as an unmistakable difference with private area banks, with around 55 percent of number of extortion cases, however pretty much 13 percent of the aggregate sum associated with such cases. The PSBs are increasingly defenseless if there should be an occurrence of expensive development related fakes ( 1 crore or above) as far as both number of extortion cases revealed and aggregate sum included

As indicated by discoveries of Deloitte (2015), number and advancement of cheats in banking area have expanded throughout the most recent two years. Around 93 percent of respondents proposed an expansion in extortion episodes and the greater part said that they had seen it in their own associations. Retail banking was recognized as the significant supporter of extortion occurrences, with numerous respondents saying that they had encountered near 50 false episodes over the most recent two years and had lost, on a normal of Rupees ten lakhs for every misrepresentation. Interestingly, study respondents showed that the non-retail fragment saw a normal of 10 extortion episodes with a rough loss of Rupees two crore for each occurrence. Numerous respondents couldn't recoup in excess of 25 percent of the misfortune. 


\section{Figure 2: Group wise summary of advance related fraud cases}

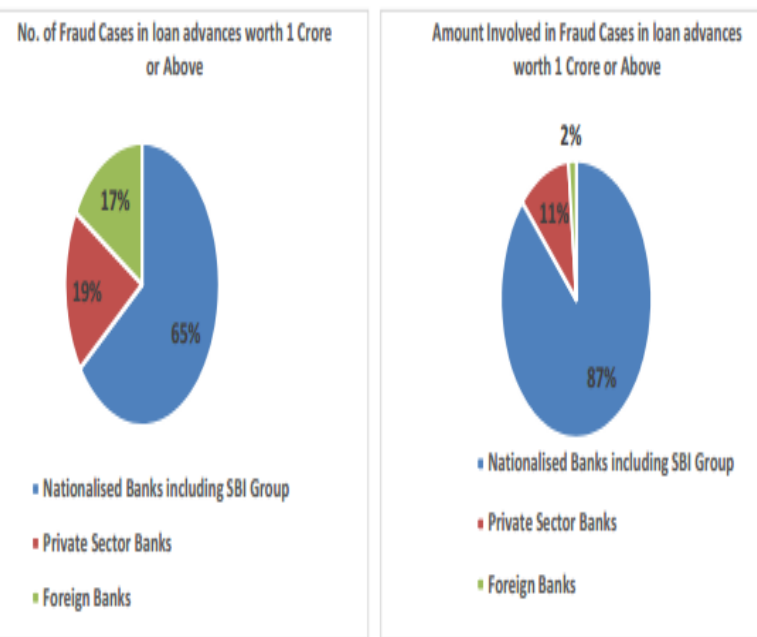

The dangers embraced by banks are as yet a reason for stress in spite of the fact that it has directed a bit. This is demonstrated by the bank security pointer. Thus, banks were stressed by poor resource quality. Framework level credit hazard is controlled by gross NPA proportion which is required to be around 5.4 percent by September 2016 and 5.2 percent in March 2017 according to RBI (2015c). Further, the proportion of focused on resources has expanded essentially over the most recent couple of years. As of September 2015, pushed and discounted resources (SWA) 4 are at 14.1 percent. The patterns anyway are different, with open segment banks having a SWA of 17 percent and private division banks having a SWA of 6.7 percent as per Mundra (2016).

\section{Figines: (yber Frauls}

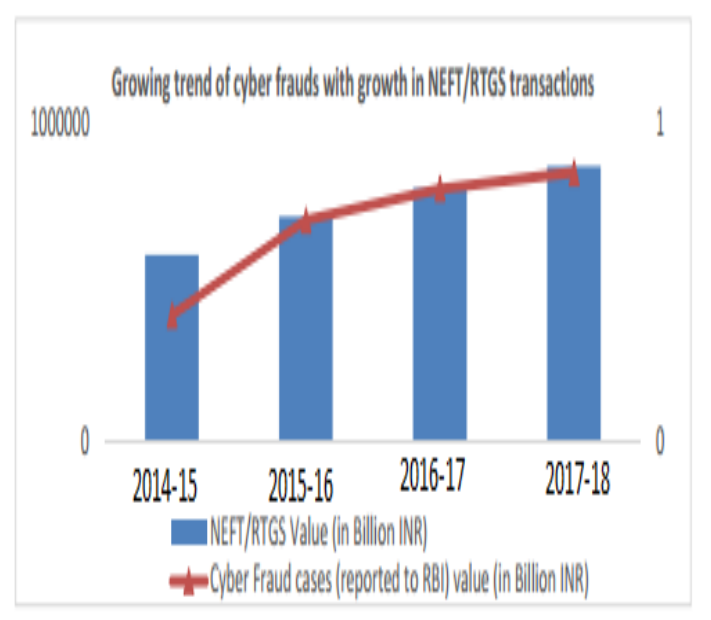

Fiquret: identity Thet Frawd

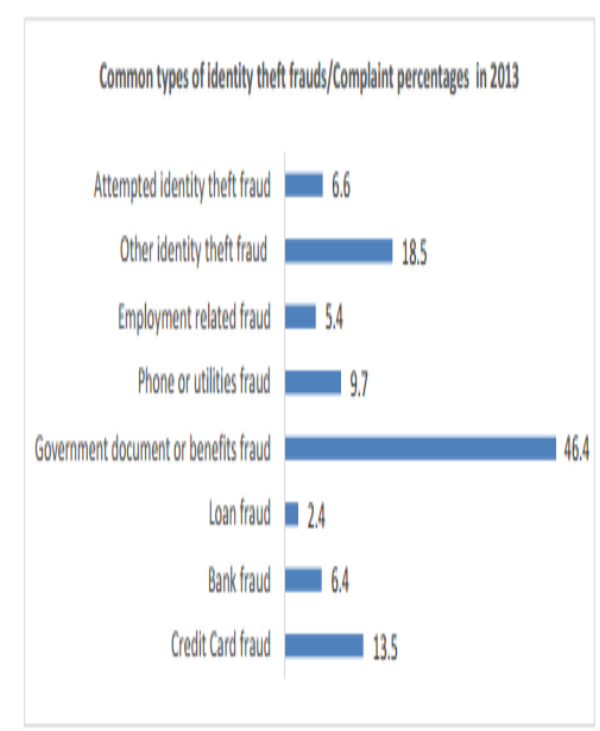

Fraud detection procedure in public sector banks: The creators dissected the procedure of extortion recognition and revealing in an open part bank and who are the different players associated with this procedure. Following is a well ordered representation of the equivalent (Figure 5).

a) First, an extortion is inside answered to senior administration of a bank. These may incorporate boss general administrators, official chiefs, executive and overseeing executive. They may likewise be accounted for to carefulness division of the bank.

b) If answered to the carefulness branch of the bank, it explores the extortion and afterward reports it to both senior administration just as the focal watchfulness commission (CVC) to whom they are required to report month to month.

c) Although $\mathrm{CVC}$ can report misrepresentation straightforwardly to researching offices like CBI, typically official conclusion to either report extortion to an outside organization or to manage it inside is made by senior administration of the bank. Contingent on size of the bank, measure of cash associated with fake action and number of outsiders included, senior administration may manage the misrepresentation inside or document a FIR and report it to either neighborhood police or CBI.

d) A panel of the RBI additionally freely screens false conduct in banks and reports its perceptions on quarterly premise to focal leading body of the RBI. The board may 13.56 .42 .4 46.4 9.7 5.4 18.5 6.6 Credit Card misrepresentation Bank extortion Loan extortion Government archive or advantages misrepresentation Phone or utilities extortion Employment related misrepresentation Other wholesale fraud misrepresentation Attempted data fraud extortion Common kinds of fraud fakes/Complaint rates in 2013 at that point report the issue to either focal cautiousness commission or service of account $(\mathrm{MoF})$.

e) Auditors, over the span of their review, may go over occurrences where exchanges in records or archives point to probability of deceitful exchanges in records. In such a circumstance, evaluator may quickly convey it to the notice of top administration and if important to review council of board 
(ACB) for fitting activity

f) Employees can likewise report deceitful movement in a record, alongside the reasons in help of their perspectives, to the properly comprised specialist (Table 1), under the informant arrangement of the bank, who may establish an examination through the extortion observing gathering (FMG). The FMG may 'hear' the concerned representative so as to acquire essential illuminations. Security ought to be accessible to such representatives under the informant arrangement of the bank with the goal that dread of exploitation does not go about as an impediment.

\section{Figure 5: Flow Chart depicting procedures post Fraud Detection and Reporting}

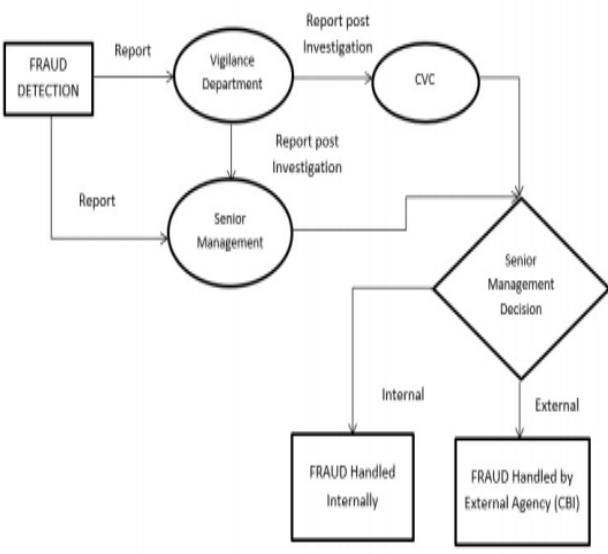

Table-3: Private/Public Banks- amount involved in fraud.

\begin{tabular}{|c|c|c|c|}
\hline $\begin{array}{c}\text { Category of } \\
\text { bank }\end{array}$ & $\begin{array}{c}\text { Amount inrolved in the } \\
\text { fraud }\end{array}$ & $\begin{array}{c}\text { Agency to whom } \\
\text { complaint should be } \\
\text { lodged }\end{array}$ & Other Information \\
\hline \multirow{3}{*}{\begin{tabular}{|l|} 
Private \\
Sectorl \\
Foreign Banks
\end{tabular}} & Rs.1 lakh and above & Statepolice & \\
\hline & $\begin{array}{l}\text { Rs.10000 and above if } \\
\text { comminited by staff }\end{array}$ & Statepolice & \\
\hline & Rs. lcrore and above & \begin{tabular}{|lr} 
Serious & fraud \\
investigation & office \\
(Ministry ofCorporate \\
Affairs)
\end{tabular} & \begin{tabular}{|l} 
In addition to state police \\
\end{tabular} \\
\hline \multirow{3}{*}{$\begin{array}{l}\text { Public Sector } \\
\text { Banks }\end{array}$} & Below Rs. 3 3core & Statepolice & \\
\hline & $\begin{array}{l}\text { Rs.3.3rore and above and up } \\
\text { to Rs.25 crove }\end{array}$ & CBI & 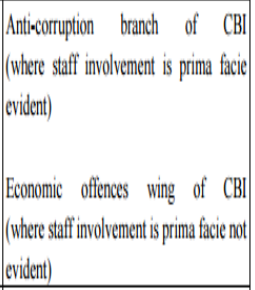 \\
\hline & More than Rs.25 crovere & CBI & \begin{tabular}{|l|} 
Banking Security and Fraud Cell (BSFC) \\
of \\
(irrespective of the involvement of a public \\
servant)
\end{tabular} \\
\hline
\end{tabular}

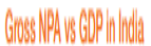

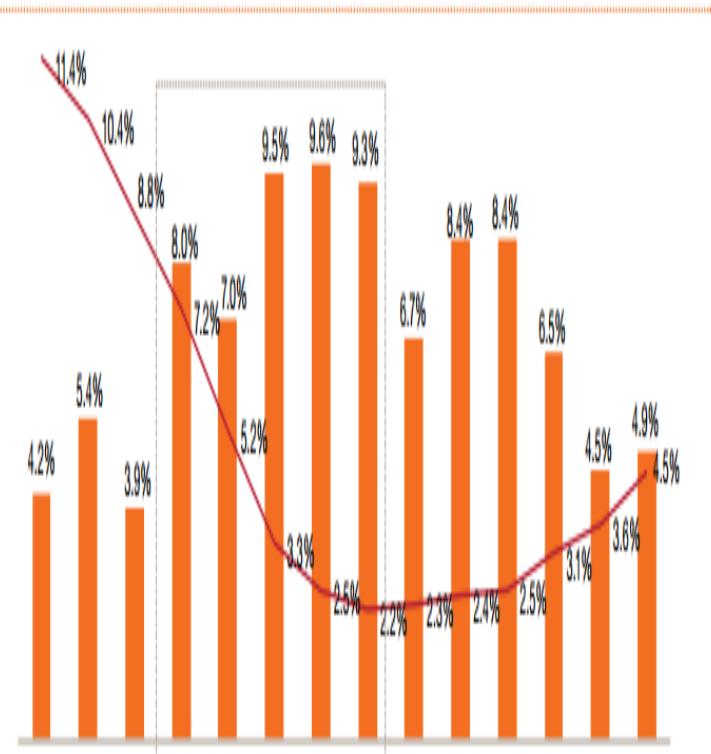

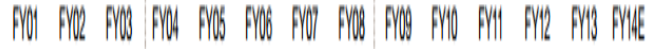

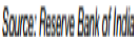

$$
\text { W }=\text { W PAP }
$$

\section{RECOMMENDATIONS FOR AN EARLY DETECTION OF FRAUDS:}

a) Independent specific unit: The legislature could consider a free particular framework of officers on the lines of all India administrations, who are outfitted with the best money related and legitimate expertise to identify monetary fakes and are equipped for completing a viable and time bound examination of such tricks. In present moment, the legislature can consider shaping this framework with a pool of business brokers, RBI and $\mathrm{CBI}$ authorities through sidelong enlistment.

b) Know your business sectors: notwithstanding know your merchant and know your client, the banks ought to likewise concentrate on know your business sectors. There ought to be a devoted cell inside each bank to survey the organization/firm to which they are loaning and the full scale monetary condition of the concerned business or market where items are showcased. This proposal even appears to be applicable with regards to the ongoing accident of the Chinese market. A few Indian assembling organizations, which were subject to import of hardware from China, couldn't begin their undertakings and produce money streams, and this thusly influenced the banks from which advances were raised.

c) Internal rating office: Banks ought to have a solid interior rating office, which assesses expensive tasks before endorsing advance. The rating organization ought to carefully assess the task based on plan of action/plan of undertaking without being impacted by brand name or credit value of the parent organization, considering current large scale monetary circumstance and introduction of the division to the worldwide economy. In the event that appraisals of inner and outer offices are not comparable then an examination must be directed to build up the reasons for such contrasts. Likewise, bank should look for administrations of no less than 2-3 
autonomous inspectors in assessment of such undertakings to anticipate odds of any conceivable arrangement.

d) Use of most recent innovation: The information gathering system in banks is obsolete and needs a modification. The banks should utilize the best accessible IT frameworks and information investigation so as to guarantee successful execution of the red hailed account (RFA) and early cautioning signs (EWS) system proposed by the RBI, which would help in a superior profiling of clients IIMB-WP N0. $50521 \mid \mathrm{P}$ a g e by examining examples of their exchanges and rendering a close continuous checking workable for banks. Additionally, we prescribe that the Institute for Development and Research in Banking Technology (IDRBT) could consider boosting advancement of pertinent programming for business banks at moderate expenses. This is crucial to upgrade their checking of suspicious and false exchanges inside the parts of their banks.

e) Monitoring exception development at provincial dimension: The RBI could consider expanding its observing ambit and scope, and should screen the anomaly developments of exchanges at territorial dimension on the lines of SEBI's electrical switch, which may be successful in following the most punctual conceivable indications of budgetary fakes.

f) Strong correctional measures for outsiders: The legislature ought to consider analyzing the job of outsiders, for example, sanctioned bookkeepers, backers, inspectors, and rating organizations that figure in records identified with bank cheats, and set up severe reformatory measures for future prevention. There is likewise a case to be made to scrutinize the affirmation/accreditations of outsiders like reviewers to choose their capability in assessing accounts containing possibly deceitful sections.

\section{CONCLUSION}

While extortion is certainly not a subject that any bank needs to manage, actually most associations experience misrepresentation somewhat. It ought to be perceived that the elements of any association (why just bank) requires a progressing reassessment of misrepresentation exposures and reactions in light of the changing condition an association experiences. Particularly given the unwavering pace of administrative change inside the financial area, these stricter administrative necessities are requesting more consideration from the board, influencing the productivity of various lines of business, and expanding expenses of consistence. The cheats might be principally because of absence of sufficient supervision of top administration, flawed motivating force instrument set up for workers, agreement between the staff, corporate borrowers and outsider organizations, frail administrative framework, absence of proper devices and innovations set up to identify early cautioning signs of a fake, absence of consciousness of bank representatives and clients; and absence of coordination among various banks crosswise over India and abroad. The brains of officers can't be perused amid the season of enlistment. Mentality of some private and some open part bank workers will be to deliberately swindle the association. What the associations can do is to build up and recheck frameworks which will raise the auspicious caution on deviations. Internet banking is the new pattern and it is digging in for the long haul. Banks must understand that the clients who utilize internet banking administrations is an incredible gathering fit for propelling searing assaults utilizing the online life, which can unsalvageable discolor the notoriety of banks. Banks would need to always screen the typology of the fake exercises in such exchanges and consistently survey and update the current security highlights to anticipate simple control by programmers, skimmers, phishes, and so forth. Banks have customarily anticipated flexibility against physical assaults and cataclysmic events; digital strength can be treated similarly. Banks ought to consider their general digital flexibility abilities over a few measurements. Society and media should request stringent activity against the culprits of monetary fakes. Early recognition, through the execution of imperative projects/programming's/framework to identify both rising dangers and the fraudster's moves, can be a fundamental advance towards containing and moderating misfortunes. Occurrence recognition that joins refined, versatile, flagging, and announcing frameworks can robotize the connection and investigation of a lot of IT and business information, just as different danger pointers, on an endeavor wide premise. Banks' observing frameworks should work $24 \times 7$, with satisfactory help for effective occurrence dealing with and remediation forms.

\section{REFERENCES}

[1] Banks, D. G. (2004). The Fight against Fraud,” Internal Auditor, April, 34-47.

[2] Baruah, S.K. (2015). RBI Chief Wants PMO to Act against Bank Frauds Worth Rs. 17,500 crore, The Hindustan Times, April 24, available at www.hindustantimes.com.

[3] Bhasin, M. L. (2012). Audit Committee Scenario and Trends in a Developing Country, School of Doctoral Studies European Union Journal,

[4] 4, 53-70. 4. Bhasin, M. L. (2013). Corporate Governance and Forensic Accountant: An Exploratory Study, Journal of Accounting, Business and Management, October, 20(2), 55-75.

[5] Bhasin, M. L. (2015). Menace of Frauds in the Indian Banking Industry: An Empirical International Journal of Pure and Applied Mathematics Special Issue 318 Study, Australian Journal of Business and Management Research, 4(2), April, 21-33.

[6] Bhasin, M. L. (2016). Contribution of Forensic Accounting to Corporate Governance: An Exploratory Study of an Asian Country, International Business Management, 10(4), 479- 492. (Forthcoming)

[7] Bhasin, M.L. (2011), Combating Cheque Fraud in Banks: The Role of Internal Auditor and Technology, Siddhant, Dec. 6, available at www.indianjournals.com.

[8] Bhasin, M.L. (2013a). An Empirical Investigation of the Relevant Skills of Forensic Accountants: Experience of a Developing Economy, European Journal of Accounting, Auditing and Finance Research, 1(2), June, 11-52.

[9] Calderon, T. and Green, B.P. (1994). Internal Fraud Leaves Its Mark: Herees How to Spot, Trace and Prevent It, National Public Accountant, 39(2), August, 17-20.

[10] Chakrabarty, K.C. (2013). Inaugural Address, National Conference on Financial Fraud, organized by ASSOCHAM, New Delhi, July 26.

[11] Ganesh, A. and Raghurama, A. (2008). Status of training evaluation in commercial bank- a case Study. Journal Of Social Sciences And Management Sciences, Vol. XXXVII, No.2, Sept, pp 137-58.

[12] Haugen, S. and Selin J.R.(1999). Identifying and 
controlling computer crime and employee fraud. Journal:

[13] Industrial Management \& Data Systems, Vol. 99 No. 8, pp. 340-4.

[14] Khanna, A. and Arora, B. (2009). A study to investigate the reasons for bank frauds and the implementation of preventive security controls in Indian banking industry, International Journal of Business Science and Applied Management, Vol. 4, No. 3

[15] Salameh, R. Ghazi Al-Weshah, G, Al-Nsour, M. and Al-
Hiyari, A. (2011). Alternative Internal Audit Structures and Perceived Effectiveness of Internal Audit in Fraud Prevention: Evidence from Jordanian Banking Industry, Canadian Social Science, Vol. 7, No. 3, pp. 40-50.

[16] Smith, E. R.(1995). A positive approach to dealing with embezzlement. The White Paper, August/September, pp 17-18. 14. Willson, R. (2006).Understanding the offender/environment dynamics for computer crimes. Information Technology and people Vol,19, No.2, pp170-186 